\title{
A crise do sistema de Bretton Woods: considerações sobre o papel do dólar na hierarquia monetária internacional
}

Flavio Alves Combat

\author{
Flavio Alves Combat \\ Professor Adjunto do Instituto de Relações Internacionais e Defesa (IRID), \\ da Universidade Federal do Rio de Janeiro. \\ Email: facombat@gmail.com \\ ORCID: https://orcid.org/0000-0001-5158-979X
}

\begin{abstract}
Resumo
O artigo propõe uma análise sobre a crise do Sistema de Bretton Woods, com o objetivo de defender a hipótese de que a profunda instabilidade do regime monetário e financeiro internacional, a partir da década de 1970, decorreu também da posição do dólar como moeda de referência no topo da hierarquia monetária internacional. Em face desse objetivo, são analisadas as diferentes iniciativas de reordenamento do sistema monetário e financeiro internacional após o fim do padrão dólar-ouro. Sustenta-se que os déficits no balanço de pagamentos, decorrentes da política externa belicista dos Estados Unidos, desempenharam papel importante na desestabilização das instituições econômicas e políticas acordadas em Bretton Woods. O texto resgata a contribuição de István Mészáros, ao analisar a importância do complexo militar industrial norte-americano no processo de esgotamento do Sistema de Bretton Woods.
\end{abstract}

\section{Palavras-chave}

Dólar, Sistema de Bretton Woods, Hierarquia monetária internacional, Complexo militar industrial

\begin{abstract}
The article proposes an analysis of the Bretton Woods System crisis, in order to defend the hypothesis that the profound instability of the international monetary and financial regime, from the 1970s onwards, also arose from the position of the dollar as a reference currency at the top of the international monetary hierarchy. Therefore, the different initiatives to reorganize the international monetary and financial system after the end of the dollar-gold standard are analyzed. The deficits in the balance of payments, which stem from the United States' warmongering foreign policy, are said to have played an important role in destabilizing the economic and political institutions agreed at Bretton Woods. The text rescues the contribution of István Mészáros, when analyzing the importance of the American military industrial complex in the process of depletion of the Bretton Woods System.
\end{abstract}

\section{Keywords}

Dollar, Bretton Woods system, International monetary hierarchy, Mlitary industrial complex 
Flavio Alves Combat

\section{Introdução}

O fim da Segunda Guerra Mundial marcou a consolidação da hegemonia econômica e política dos Estados Unidos e de uma configuração internacional das relações sociais distinta daquela que, nos séculos XVIII e XIX, esteve centrada na Europa. Todavia, a superação do modelo político e econômico europeu e a consolidação do modelo norte-americano, sustentado pela defesa dos valores do "american way of life", inauguraram um período de adensamento de contradições do capitalismo.

O artigo propõe uma análise da crise do Sistema de Bretton Woods, com o objetivo de defender a hipótese de que a profunda instabilidade do regime monetário e financeiro internacional, a partir da década de 1970, decorreu também da posição do dólar como moeda de referência internacional.

Com base na análise das contradições do dólar, investiga-se a proposição de que, a partir da década de 1970, com a escalada dos custos da Guerra do Vietnã e com a desaceleração do crescimento das economias europeia e japonesa, os fundamentos do regime monetário e financeiro internacional, sustentados por Washington desde o Acordo de Bretton Woods (1944), enfrentaram um processo de crise. A partir dessa hipótese, são analisadas as sucessivas tentativas de reordenamento do sistema monetário e financeiro internacional a partir da década de 1970, destacando as suas principais consequências.

O texto resgata a contribuição de István Mészáros e propõe uma relação entre o modus operandi do complexo militar-industrial dos Estados Unidos durante a Guerra Fria e a crise do Sistema de Bretton Woods. Argumenta-se que a Guerra do Vietnã (1965-1975) exacerbou as contradições do padrão norte-americano de produção e consumo em massa, resultando em problemas de grande peso, sobretudo para as economias que utilizavam o dólar como reserva de valor.

\section{De Bretton Woods ao fim do padrão dólar-ouro}

O fim da Segunda Guerra Mundial apresentou uma série de desafios aos Estados Unidos. Dentre os principais desafios econômicos, destacava-se o caos monetário e financeiro internacional, diretamente associado à devastação dos principais países europeus durante a Segunda Guerra.

Ao caracterizar a situação da Europa no período que sucedeu imediatamente a Segunda Guerra, Munhoz destacou que:

Ao final da guerra, a Europa encontrava-se arrasada. Os países mais industrializados do continente passaram da situação de credores para aquela de devedores de vultosas somas. A situação social era preocupante. Não havia energia, comida e habitações para suprir as necessidades básicas da população e suportar a retomada da produção. As instituições do velho continente haviam desmoronado e surgiu um vácuo de poder principalmente no Centro e Leste da Europa. Ancorada no poderio do Exército Vermelho e de ativistas locais, a URSS controlava a maior parte dessa região. (...) Nesse contexto, a escassez de energia, principalmente carvão e eletricidade, criava dificuldades adicionais para a expansão da produção industrial. A escassez de produtos desencadeava um processo inflacionário que corroía o salário dos trabalhadores, levando-os a mobilizações para a recuperação do poder aquisitivo. (MUNHOZ, 2004[a], p. 545.) 
Flavio Alves Combat

Reorganizar a arquitetura mundial de poder e consolidar a hegemonia norte-americana eram objetivos que dependiam sobremaneira da fundação de um novo e bem-sucedido sistema monetário e financeiro internacional. Assim, em julho de 1944, 44 países, representados por 730 delegados, reuniram-se na cidade norte-americana de Bretton Woods, no estado de New Hampshire, para discutir a reorganização do sistema monetário e financeiro internacional no âmbito da Conferência Monetária e Financeira das Nações Unidas (OBERDORFER, 1991, p. 47). 0 resultado das negociações foi o Acordo de Bretton Woods.

Abordagens distintasi assinalam um vasto conjunto de interesses envolvidos no Acordo de Bretton Woods: a restauração das economias europeias, o objetivo de fomentar o pleno emprego, o estímulo ao comércio internacional. Em função dos objetivos do artigo, o principal resultado do Acordo a ser analisado é a estruturação de um conjunto de regras e de instituições que regularam as relações monetárias e financeiras entre os países mais industrializados do mundo, entre 1944 e 1971.

As razões políticas e econômicas que motivaram o Acordo de Bretton Woods remontavam a uma série de questões que marcaram as primeiras décadas do século XX: a desorganização do sistema monetário e financeiro internacional entre a Primeira e a Segunda Guerra Mundial, a Grande Depressão da década de 1930 e a desestabilização da ordem monetária e financeira mundial durante a Segunda Guerra Mundial.

O fim da Primeira Guerra Mundial foi marcado pela retomada do padrão ouro. Em 1925, a Grã-Bretanha adotou novamente a conversibilidade da libra em ouro, com a mesma paridade que vigorava antes da Guerra. Num primeiro momento, a retomada do padrão ouro, com a conversão das moedas na mesma paridade que vigorava antes da Primeira Guerra, acentuou o desajuste entre as economias deficitárias e as superavitárias. Estados Unidos e França, ao sustentarem a depreciação de suas moedas a partir de 1926, assumiram a dianteira das exportações mundiais (POLLARD, 1985, p. 158). Como países superavitários, conseguiam esterilizar o aumento de suas reservas de ouroii e evitaram, dessa forma, pressões inflacionárias decorrentes da variação de suas bases monetárias. Simultaneamente, drenaram as reservas de ouro britânicas e de outros países deficitários (que mantinham paridades apreciadas).

Pelo princípio do lastreamento e da conversibilidade das moedas em ouro, a transferência de ouro para os Estados Unidos e para a França gerou uma contração das bases monetárias da Grã-Bretanha e de outros países deficitários. A solução, num primeiro momento, foi a utilização de políticas nacionais de crédito para amenizar o impacto da retração da atividade econômica, às custas do desrespeito das "regras do jogo": o aumento da base monetária sem lastro em ouro (BORDO, 1992, p.11).

Os desajustes entre as economias nacionais foram agravados na década de 1930, durante a Grande Depressão. A Depressão da década de 1930 foi marcada particularmente por um desajuste entre as medidas tomadas individualmente por cada um dos Estados para tentar reverter suas respectivas crises econômicas unilateralmente. Depreciações cambiais foram empregadas na tentativa de estimular as exportações e de reduzir os déficits do balanço comercial. Em combinação, as políticas cambiais empreendidas naquele período fragilizaram ainda mais a economia mundial, contribuindo com o agravamento das "espirais deflacionárias" "iii de diversos países. A redução da renda nacional, a retração da demanda, o desemprego em massa e o declínio acentuado e generalizado do comércio mundial (exacerbado pela disseminação de barreiras comerciais) foram agravados em função do desencontro entre as políticas econômicas nacionais (POLLARD, 1985, p. 170-172).

O contexto em que o Acordo de Bretton Woods foi firmado foi marcado, portanto, pela instabilidade nas regras de funcionamento da configuração monetária e financeira internacional e 
Flavio Alves Combat

pelo aprofundamento dos problemas econômicos dos principais países europeus industrializados em função da Segunda Guerra Mundial.

O principal fundamento de Bretton Woods era o padrão dólar-ouro, que estabelecia a conversibilidade do dólar em ouro numa paridade fixa e consolidava a centralidade da moeda norte-americana na configuração econômica e política internacional. O padrão dólar-ouro criou, simultaneamente, um padrão homogêneo de comparação das diversas moedas, condição fundamental para a nova arquitetura monetária e financeira internacional.

O processo de fortalecimento do dólar em relação as outras moedas remontava, de fato, ao período anterior à Segunda Guerra, durante o qual a conversibilidade do dólar em ouro havia sido mantida. A consolidação do dólar como moeda central da configuração internacional não foi, portanto, mero resultado de um acordo. O peso da hegemonia norte-americana assegurou a Washington a capacidade de suplantar alternativas, como, por exemplo, a proposta britânica de criação de uma moeda mundial (o "bancor"), defendida por John Maynard Keynes (SEYMOUR, 1974, p. 205).

Na prática, o Acordo de Bretton Woods estabeleceu um conjunto de regras de conversibilidade, que norteavam os regimes cambiais dos países signatários. As paridades das moedas em relação ao ouro e, consequentemente, em relação ao dólar poderiam oscilar em apenas $1 \%$, o que assegurava ao dólar a centralidade no sistema financeiro e monetário internacional. Dessa forma, sanaram-se os problemas decorrentes da fragmentação monetária e financeira das décadas anteriores.

Paralelamente, a estabilidade do sistema monetário e finance ${ }^{1}$ iro arquitetado em Bretton Woods dependia do arranjo institucional organizado por Washington, que contribuía com a manutenção da liquidez internacional e com a promoção de ajustes entre as economias dos países signatários do Acordo.

A manutenção da paridade dólar-ouro dependia fundamentalmente da capacidade dos Estados Unidos em manter a liquidez internacional num patamar ajustado ao nível de crescimento da economia mundial. Essa manutenção foi assegurada, até o início da década de 1970, através de sucessivos déficits no balanço de pagamentos norte-americano, sob a forma de fluxos de capitais dos Estados Unidos para o exterior. Desse modo, até 1971, os investimentos diretos e a ajuda militar e econômica aos países europeus reverteram a escassez de dólares, assegurando à Europa Ocidental as condições básicas para a expansão econômica experimentada entre meados da década de 1940 e o início da década de 1970 (LUNDESTAD, 1986, p. 65).

Os ajustes entre as economias superavitárias e as deficitárias, e a consolidação da estabilidade monetária internacional foram assegurados, por sua vez, por uma nova arquitetura institucional centrada no Fundo Monetário Internacional (FMI) - originalmente criado para financiar os países com sérios déficits no balanço de pagamentos - e pelo controle sobre o fluxo de capitais, que debelava ações especulativas ao assegurar a manutenção da rígida paridade entre as moedas nacionais.

A utilização das taxas fixas de câmbio como um mecanismo de ajuste, associada ao controle dos fluxos de capital, garantiu a consolidação da estabilidade da configuração monetária e financeira internacional e assegurou, ao mesmo tempo, um grau de autonomia de cada nação na gestão de sua política monetária (dentro das regras acordadas).

Todavia, os problemas vislumbrados pelos Estados Unidos ao final da Segunda Guerra Mundial não se restringiam à reorganização financeira e monetária internacional. Uma nova reorganização do poder sinalizava o início de uma era de grandes desafios e oportunidades. No 
Flavio Alves Combat

contexto de grandes transformações, o papel desempenhado pelos Estados Unidos no mundo dependia, claramente, da capacidade de convencer os outros países sobre a universalidade e sobre a desejabilidade dos interesses e dos valores norte-americanos, fundamentos centrais de uma hegemonia.

Assim, a consolidação da hegemonia norte-americana e a operacionalização das propostas acordadas em Bretton Woods não dependiam somente de um novo sistema institucional que ajustasse e estabilizasse as políticas econômicas de cada Estado. A implementação e o funcionamento, de facto, do aparato institucional desenvolvido no Acordo de Bretton Woods, condição básica para a afirmação da centralidade internacional do dólar, foram assegurados, em grande medida, pelo Plano Marshall (1948-1951).

Imediatamente após a Segunda Guerra Mundial, a tentativa norte-americana de reverter a influência soviética em países do Leste da Europa (Polônia, Tchecoslováquia, Romênia e Bulgária), com base na "diplomacia do dólar forte", fracassou diante da obstinação de Stalin em não compactuar com as instituições internacionais que sustentavam o poder dos Estados Unidos. Segunda maior potência no pós-Guerra, a União Soviética e o seu modelo de organização social se opunham frontalmente à organização da configuração internacional centrada no modelo social capitalista norte-americano. À Washington apresentava-se, portanto, um duplo desafio de grandes proporções: impedir o avanço da esfera de influência soviética e recuperar a economia europeia, principal mercado consumidor de produtos norte-americanos no exterior. Portanto, com um investimento total de aproximadamente US\$13,3 bilhões, o Plano Marshall (1948-1951) ocupou posição central na política externa dos Estados Unidos após a Segunda Guerra Mundial.

As consequências desestabilizadoras da Segunda Guerra Mundial sobre a Europa figuravam, em 1945, entre as principais preocupações dos Estados Unidos. Naquele contexto, fortalecer a Europa era condição essencial não apenas para restaurar as principais vias de comércio internacional, mas também para conter o avanço do comunismo - muito embora, do ponto de vista prático, a União Soviética não estivesse em condições de empreender uma arriscada e cara incursão pela Europa Ocidental.

No início da década de 1950, o sucesso do Plano Marshall era inquestionável. O PIB dos países da Europa Ocidental auxiliados pelo Plano havia aumentado $32 \%$ em relação ao PIB de 1948. A produção agrícola cresceu $11 \%$, acompanhada de um crescimento ainda mais expressivo da produção industrial, que aumentou $40 \%$. A economia norte-americana experimentou um crescimento igualmente expressivo, alcançando níveis elevados de produção, renda e consumo (HOGAN, 1987, p. 267).

A recuperação dos mercados europeus e o restabelecimento dos fluxos comerciais internacionais não eram, entretanto, os únicos objetivos norte-americanos com o Plano Marshall. 0 rompimento do modelo econômico e da arquitetura mundial de poder centrados na Europa era um interesse central dos Estados Unidos. Nessa perspectiva, o Plano Marshall foi essencial para os Estados Unidos porque lançou as bases para a consolidação de uma nova ordem internacional centrada na hegemonia norte-americana, através da implementação do "american way of life" na Europa sob a forma de regimes nacionais de produção e consumo em massa. Ao viabilizar o funcionamento das instituições criadas pelo Acordo de Bretton Woods (1944), o Plano Marshall criou também as condições necessárias para o desenvolvimento do Estado de Bem-Estar Social e para a implementação da relação salarial fordista na Europa (HOGAN, 1987, p. 280).

Dessa forma, sob a liderança norte-americana, fundaram-se as bases de um período de expansão do produto, do comércio mundial e de estabilidade financeira, com taxas de inflação controladas. O período entre 1945 e 1975 tornou-se conhecido como a "era de ouro" da economia norte-americana. 
Flavio Alves Combat

\section{A crise do sistema de Bretton Woods}

A desaceleração das principais economias do mundo a partir da década de 1970 - marcada pela retração das taxas de crescimento do produto, da produtividade e dos lucros, além da aceleração da inflação e do aumento do desemprego - marcou não apenas a erosão da suposta viabilidade de exportação do "sonho americano", mas inaugurou também um período de declínio da capacidade norte-americana de convencer outros países acerca da universalidade dos interesses dos Estados Unidos, um fundamento, em si, do poder hegemônico.

Embora alguns indicativos do processo de deterioração das bases de sustentação da economia mundial já pudessem ser observados desde a década de 1960, sobretudo em virtude dos problemas criados pelo padrão de financiamento externo do déficit público norte-americano (especialmente decorrente dos vultosos gastos com a Guerra do Vietnã), somente em 1971 a ordem monetária e financeira internacional forjada no Acordo de Bretton Woods tornou-se insustentável. Para financiar o seu crescente déficit público, os Estados Unidos dependiam da aceitação internacional do dólar como dinheiro e, em especial, da sua utilização como reserva de valor. Assim, os demais países do sistema internacional precisavam ser convencidos e, em alguma medida, coagidos, por pressão política e econômica, a manterem reservas em títulos da dívida norte-americana e em ativos financeiros referenciados no dólar. Num segundo plano, também era importante que as transações internacionais (comerciais e financeiras) utilizassem o dólar como unidade de conta, assegurando aos Estados Unidos o controle sobre a emissão da única moeda aceita internacionalmente com pouco ou nenhuma restrição. Esse modelo de organização do sistema financeiro internacional, com o dólar no topo da hierarquia monetária, era especialmente vantajoso aos EUA, na medida em que, ao menos em tese, representava a possibilidade de endividamento irrestrito.

A mais significativa manifestação do acirramento dos problemas econômicos mundiais gerados pela economia norte-americana foi a abolição do padrão dólar-ouro em 1971, a base do regime monetário e financeiro internacional fundado em 1944.

A intervenção norte-americana no Vietnã, nas décadas de 1960 e 1970, deflagrou as primeiras consequências desestabilizadoras da hegemonia norte-americana. À medida que a Guerra do Vietnã se prolongava, aprofundava-se a insustentabilidade do padrão de financiamento da economia norte-americana. A análise desenvolvida por István Mészáros (1989) é notadamente interessante no que se refere ao papel do complexo militar-industrial norte-americano no esgotamento dos fundamentos da economia dos Estados Unidos durante a Guerra do Vietnãiv. Mészáros analisou as transformações do padrão de produção e consumo no período entre 1945 e 1975, centrando as suas considerações na tendência de redução da "taxa de uso" (o "tempo de utilização") das mercadorias (incluindo a força de trabalho) e no papel do complexo militarindustrial no sistema capitalista mundial no período em questão.

De acordo com Mészáros, antes do pleno desdobramento histórico das potencialidades produtivas do capital e da produção e do consumo em massa daí decorrentes, à medida que variações da produtividade permitiam uma redução do tempo de trabalho social alocado na produção de bens de consumo e um aumento da parcela do tempo de trabalho social alocado na produção de "bens duráveis", a riqueza e o nível de desenvolvimento econômico de um país poderiam ser medidos pela relação entre o quantum de mercadorias duráveis e o quantum de mercadorias não reutilizáveis produzidas. Assim, poder-se-ia esperar que uma parcela crescente de recursos de uma sociedade fosse destinada à produção de bens reutilizáveis.

Entretanto, o sistema capitalista mundial vigente entre o fim da Segunda Guerra Mundial e a primeira metade da década de 1970 enfrentou uma reversão da tendência acima apontada: a produção em massa de bens "descartáveis", que antes eram relativamente duráveis, foi transformada num dos fundamentos da reprodução social do capital. 
Flavio Alves Combat

Do ponto de vista do capital, desde que a demanda efetiva seja assegurada, quanto menor a taxa de uso das mercadorias, melhor, pois isso "gera" demanda por outras mercadorias que antes poderiam ser reutilizadas. Nesse sentido, a produção e o consumo em massa "destrutivos" são perfeitamente consistentes com a lógica da reprodução ampliada do capital, não importando o quão absurdamente dissipador e destruidor de recursos naturais e sociais seja um procedimento produtivo, desde que o seu produto possa ser lucrativamente realizado. Como ressaltou Mészáros, ao analisar as consequências da transformação dos meios de produção em capital:

\begin{abstract}
[Uma vez convertidos em capital, os meios de produção] têm de se opor às necessidades humanas, se a lógica do capital o exige, sobrepondo às necessidades humanas existentes e potencialmente emergentes as assim chamadas 'necessidades da produção', que correspondem diretamente ao interesse de salvaguardar a expansão do capital. Similarmente, avanços no 'know-how' científico podem ser agora transformados em efetivos meios de produção, não para serem realmente empregados no campo ou em atendimento das necessidades humanas, mas somente se isto acentua os interesses do sistema do capital. (MÉSZÁROS, 1989, p. 29)
\end{abstract}

A implementação da "obsolescência planejada" pelo capital foi exemplificada, a partir de 1945, pela subutilização de bens e serviços que possuíam um potencial de utilização muito maior, pela imposição de capacidade produtiva inutilizável e por diversos casos de produção e consumo destrutivos de recursos. Todavia, garantir a motivação para descartar bens perfeitamente utilizáveis não é tarefa fácil. Garantias precisavam ser encontradas, em escala ampla e de forma institucionalizável. Nessa perspectiva, a expansão, coordenada pelo Estado norte-americano, do complexo militar-industrial funcionou, entre 1945 e meados da década de 1970, como o principal meio de sustentação da produção e do consumo destrutivos e amenizou, ao menos temporariamente, uma importante barreira à reprodução do capital: as crises de acumulação e de subconsumo.

As transformações impulsionadas pela Segunda Guerra Mundial redefiniram profundamente a organização da estrutura econômica mundial. Após 1945, o dinamismo do complexo militarindustrial, já existente na época do Acordo de Bretton Woods explica, em grande medida, a acelerada expansão das economias europeia e norte-americana. O Acordo de Bretton Woods favoreceu a reprodução ampliada da indústria bélica ao regulamentar e institucionalizar o sistema monetário e financeiro internacional, criando as bases de financiamento do complexo militarindustrial, altamente dissipador de recursos.

A grande inovação introduzida no capitalismo pelo complexo militar-industrial foi a supressão da diferença entre consumo e destruição das mercadorias, que dificultava a contínua reprodução ampliada do capital. Deve-se ressaltar, no entanto, que a produção e o consumo "destrutivos" não são uma característica recente do capitalismo, mas uma tendência do capital, historicamente verificável em diversos períodos. O que variou após a Segunda Guerra foi a magnitude assumida por essa tendência, a sua generalização e a sua transformação no modelo de normalidade do sistema capitalista. A inovação no capitalismo contemporâneo reside precisamente na dimensão quantitativa alcançada pelo complexo militar-industrial na dissipação destrutiva de recursos, que implicou transformações qualitativas: a conformação de uma poderosa contratendência às crises de superacumulação de capital e de subconsumo. Conforme enfatizou Mészáros:

Além do mais, o método para solucionar os problemas acumulados pela ativação dos mecanismos de destruição não é de modo algum algo radicalmente novo, que tivesse surgido apenas com o desenvolvimento recente do capitalismo. Pelo contrário, esta é precisamente a maneira pela 
Flavio Alves Combat

qual o capital tem conseguido se livrar, ao longo de sua história, das situações de crise: i.e., destruindo sem cerimônia unidades de capital excedentes e não mais viáveis, incrementando convenientemente deste modo a concentração e a centralização do capital, reconstituindo desta maneira a rentabilidade do capital social total. A inovação do capitalismo "avançado" e de seu complexo militar-industrial é que agora a prática originária - que atendia às exigências excepcionais e emergenciais das crises - foi generalizada e tornou-se o modelo de normalidade para a vida cotidiana de todo o sistema orientado no sentido da produção para destruição como procedimento corrente, em conformidade com a lei tendencial da taxa de uso decrescente, capaz de se aproximar, teoricamente, do índice zero. (MÉSZÁROS, 1989, p. 89)

\section{É desse modo, portanto, que esse "modelo de normalidade" do sistema capitalista} possibilitou que crises de superacumulação de capital fossem postergadas e coibidas, embora, de forma alguma, extintas. Além disso, no período após a Segunda Guerra Mundial, o realinhamento entre os interesses do capital e os interesses do Estado conferiu ao complexo militar-industrial a tão almejada institucionalização. Como destacou Mészáros:

Nem é mais preciso considerar as dificuldades devidas aos limites dos apetites humanos e das rendas pessoais, pois o "consumidor" não é mais simplesmente o agregado disponível de indivíduos limitados. De fato, graças à significativa transformação das estruturas produtivas dominantes da sociedade capitalista do pós-guerra, em paralelo com o correspondente realinhamento de sua relação com o Estado capitalista (tanto por motivos econômicos, quanto para assegurar a necessária legitimação ideológicopolítica), de agora em diante a fusão mítica entre produtor/comprador/consumidor não é nada menos que "a própria Nação". (...) Somente "a Nação" poderia assegurar a satisfação da dupla exigência de proporcionar, de um lado, um fundo inexaurível, tornando possível a autorreprodução ampliada do capital, e, por outro, um fosso sem fundo que tragasse todo o desperdício resultante. (MÉSZÁROS, 1989, p. 86)

O vínculo estreito entre a economia dos Estados Unidos e as economias dos outros países capitalistas foi um fator essencial para o funcionamento "saudável" da nova ordem internacional consolidada após 1945. Se, por um lado, os gigantescos orçamentos de defesa dos Estados Unidos durante a Guerra do Vietnã estimulavam a expansão econômica dos países capitalistas avançados, por outro os países europeus e o Japão financiavam a economia norte-americana com os recursos acumulados, graças ao sucesso de suas respectivas economias. A expansão das economias centrais do bloco capitalista após 1945 não pode, nesse sentido, ser plenamente explicada se não for compreendida a importância da indústria bélica, considerando-se a estreita relação entre as economias europeias, japonesa e norte-americana.

O complexo militar-industrial norte-americano ocupou, por certo, uma posição dominante a partir de 1945, sendo rivalizado somente pelo poderio militar soviético. A magnitude dos gastos militares dos Estados Unidos durante a Guerra do Vietnã, no entanto, foi suficiente para saturar o padrão de financiamento externo da economia norte-americana, basicamente assegurado pela imposição do dólar como moeda central da configuração internacional desde o Acordo de Bretton Woods. O padrão dólar-ouro, na realidade, conferiu aos Estados Unidos, entre 1945 e 1971, uma aparente capacidade de autofinanciamento sem limites, às custas, na realidade, da expropriação do excedente produtivo dos Estados signatários de Bretton Woods. Assim, já na década de 1960, tornou-se claro que, se por um lado, o padrão dólar-ouro atendia, imediatamente após a Segunda Guerra Mundial, a necessidade de superar a escassez internacional de dólares e de criar um sistema de referenciação cambial confiável que debelasse a instabilidade monetária e financeira 
Flavio Alves Combat

mundial, por outro as regras de conversibilidade e de lastreamento em ouro das moedas europeias engessava substancialmente as principais economias do mundo, limitando sobretudo o campo de manobra da política econômica na Europa (FONTAINE, 2006, p. 47-50).

O processo de enfraquecimento do dólar foi uma decorrência, sobretudo, dos problemas de financiamento externo dos Estados Unidos. A análise das contas nacionais norte-americanas do período entre 1945 e 1975 (NIPA, 1945-1975) revela que, durante toda a década de 1960, os EUA apresentaram um superávit no balanço comercial e nas transações correntes. Embora, já segunda metade da década de 1960, o superávit comercial norte-americano tenha começado a diminuir, a balança comercial norte-americana só se tornou deficitária a partir de 1971.

A maior parte do déficit no balanço de pagamentos norte-americano, durante a década de 1960, era causado, portanto, pelo fluxo de capitais dos Estados Unidos para o exterior, através de investimentos diretos e da ajuda militar e econômica aos países europeus, justificados pelo contexto da Guerra Fria. A partir da segunda metade da década de 1960 e início dos anos 1970, a saída de capitais norte-americanos foi intensificada à medida em que os gastos com a Guerra do Vietnã aumentavam, gerando um problema de financiamento no balanço de pagamentos, que passou a ser coberto por ativos de curto prazo, referenciados no dólar.

Paradoxalmente, a Guerra do Vietnã e o déficit público norte-americano, que pressionaram a demanda interna dos Estados Unidos (aumentando as importações), foram sustentados por uma política monetária norte-americana expansionista, com baixas taxas de juros, que desestimulavam ainda mais a entrada de capitais de curto prazo nos Estados Unidos. À medida que os dólares afluíam para o exterior, alguns Estados europeus (a França, num primeiro momento, seguida pela Grã-Bretanha), apoiados pelo sistema de conversibilidade cambial dólar-ouro, iniciaram um processo de drenagem do metal que, teoricamente, lastreava toda a base monetária norteamericana.

Durante a década de 1960, os Estados Unidos conseguiram manter a estabilidade do dólar pressionando a Europa e o Japão a não apelarem para a conversibilidade do dólar em ouro. Porém, em 1971, perante a insustentabilidade do padrão de financiamento externo da economia norte-americana, a conversibilidade do dólar em ouro foi abandonada e com ela a estabilidade do sistema monetário e financeiro internacional.

Os primeiros sinais de desestabilização do Sistema de Bretton Woods repercutiram, também, sobre as políticas de "consenso" entre capital e trabalho, centrais para o Estado do BemEstar Social dos "anos dourados" (1945-1971). A partir do início da década de 1970, as políticas de pleno-emprego - que haviam permitido que problemas centrais do capitalismo fossem apresentados, por exemplo, como disfunções temporárias de caráter essencialmente tecnológico, criando a ilusão de integração permanente do trabalho - começaram a ruir. O desemprego em massa inflamou uma contradição capitalista: a não utilização da força de trabalho socialmente disponível, com reflexos sobre a renda e o consumo agregados. Como destacou Mészáros (1989, p. 47), a força de trabalho não é apenas um fator de produção, como nos propõem as simplificações neoclássicas, mas também o consumidor de massa tão vital para a reprodução ampliada do capital.

Duas questões chamam a atenção no período que sucedeu imediatamente o fim do padrão dólar-ouro, em 1971.

A primeira questão refere-se ao fato de que a Guerra do Vietnã não apenas desmoralizou e dividiu a nação norte-americana no plano doméstico, mas foi também o marco inicial de uma crescente perda de credibilidade do dólar no sistema internacional, dificultando sua reprodução como equivalente geral e como reserva de valor no espaço internacional. A fragilização da economia norte-americana e a recusa dos países europeus em continuar financiando os Estados Unidos às custas do sacrifício de suas próprias economias acirraram, portanto, a incapacidade do 
Flavio Alves Combat

dólar de exercer mundialmente a função social de dinheiro. Para os Estados Unidos, a sustentação do dólar no topo da hierarquia monetária internacional tinha uma grande vantagem: a aparente capacidade de autofinanciamento sem limites, precisamente por se endividarem na moeda que emitiam e que era referência internacional. Portanto, além de deflagrar o colapso do padrão dólarouro, a Guerra do Vietnã marcou o início de um processo de erosão da credibilidade do dólar no sistema internacional.

A segunda questão que deve ser considerada, à luz das transformações deflagradas na década de 1970, é o aparente paradoxo entre a fragilização da hegemonia norte-americana e a sustentação da centralidade internacional do dólar. Se, em 1971, os Estados Unidos aboliram o padrão dólar-ouro, dentre outros motivos pela pressão europeia, e mesmo assim o dólar manteve a sua posição central na hierarquia monetária e financeira internacional, como podemos sustentar 0 argumento de fragilização do poder hegemônico norte-americano?

A sustentação da centralidade internacional do dólar após o fim do padrão dólar-ouro não é, na realidade, incompatível com a tese de que, a partir de 1971, os Estados Unidos experimentaram uma fragilização do seu poder hegemônico. De fato, o posicionamento internacional do dólar a partir de 1971 é explicado pelo contexto da Guerra Fria, pela inexistência de um Estado que reunisse as condições necessárias para assumir a dianteira da hegemonia econômica e política internacional, e ainda pela centralização do capital financeiro internacional nos Estados Unidos.

No início da década de 1970, a retórica anticomunista defendida pelos Estados Unidos encontrava um terreno particularmente fértil nos países da Europa Ocidental. A suposta disposição soviética em invadir a Europa Ocidental era amplamente postulada pela Casa Branca, que traçava, numa perspectiva ideológica, um cenário sombrio caso a superioridade militar e econômica dos Estados Unidos não estivesse a serviço da contenção do comunismo. Naquele contexto, embora a crença na universalidade dos interesses norte-americanos estivesse em franca decadência, era interessante aos governos capitalistas europeus aceitarem a liderança exercida pelos Estados Unidos, única potência capaz de rivalizar com a União Soviética. Cabe enfatizar, portanto, que a aceitação da liderança norte-americana, após 1971, não era fundamentada pela crença inquestionável na universalidade dos interesses dos Estados Unidos. Mesmo a suposta necessidade de contenção do comunismo já era questionada, tendo em vista que, desde o final da década de 1960, os principais movimentos de resistência social no Terceiro Mundo assumiram a forma de lutas contra as ditaduras (algumas delas, apoiadas pelos Estados Unidos).

A reprodução da coalizão internacional centrada no poder norte-americano dependia, sobremaneira, da sustentação da centralidade internacional do dólar. Com o fim do padrão dólarouro, as restrições sobre as economias europeias e japonesa, impostas pelo sistema de conversão cambial ancorada numa paridade fixa, foram relaxadas e as economias do resto do mundo perceberam uma maior margem de manobra para a política econômica (por exemplo, a possibilidade de emitir moeda sem lastro em ouro). O desenvolvimento da forma mais avançada de moeda de crédito a partir de 1971 (o padrão dólar, não conversível) afrouxou os laços que atavam excessivamente a economia mundial e que transferiam o peso dos problemas econômicos norte-americanos para a Europa e para o Japão.

No começo da década de 1970, nenhum outro país do bloco capitalista possuía condições reais de impor a centralidade internacional de sua moeda, com base, por exemplo, num sistema institucional análogo ao criado no Acordo de Bretton Woods. Tampouco existia uma potência que rivalizasse com os norte-americanos em poder militar, num contexto que o principal adversário, a União Soviética, já demonstrava fragilidade e dificuldade para acompanhar a corrida armamentista (DUKES, 1990, p. 90-91). 
Flavio Alves Combat

Cabe enfatizar também que, nas décadas seguintes a 1970, a centralidade do dólar foi assegurada não apenas pela inexistência de alternativas viáveis à hegemonia norte-americana, mas também pela habilidade dos Estados Unidos centralizarem a gerência do capital financeiro. A perpetuação do controle norte-americano sobre as altas finanças foi explicada, em parte, pela bem-sucedida configuração institucional erigida através do Acordo de Bretton Woods, pois as principais instituições econômicas mundiais eram influenciadas prioritariamente pela Casa Branca. Nesse sentido, o padrão dólar foi igualmente interessante para os EUA, pois desatava o capital financeiro das várias restrições até então impostas pela necessidade do lastro monetário em ouro.

A sustentação da centralidade internacional do dólar, mesmo após o fim do padrão dólarouro, não se traduziu, todavia, numa reprodução estável da configuração internacional. A dificuldade de reorganização do sistema monetário e financeiro internacional, e a indefinição de regras de conversibilidade cambial foram características marcantes de um período de grande instabilidade e incertezas.

\section{II. a) 0 sistema de flutuação cambial "suja"}

Em agosto de 1971, face aos graves problemas econômicos norte-americanos gerados pela excessiva apreciação do dólar (inflação, fuga de capitais, desaceleração das taxas de crescimento do produto e da renda), os EUA depreciaram a moeda norte-americana. A política cambial norteamericana precipitou um encontro entre os governantes do Grupo dos Dez ${ }^{v}$, realizado em dezembro de 1971, no Instituto Smithsoniano em Washington. O encontro deu origem ao Acordo Smithsoniano (1971), através do qual os países do G10 concordaram em apreciar as suas respectivas moedas em relação ao dólar (GUTTMANN, 1994, p. 138).

O Acordo Smithsoniano marcou também a definitiva abolição do sistema de conversibilidade cambial baseado numa paridade fixa entre o dólar e as outras moedas. A partir de 1971, adotou-se um sistema cambial baseado em bandas de flutuação controladas. Assim, entre 1971 e 1973, as principais moedas do mundo foram realinhadas e a banda de flutuação - fixada no Acordo de Bretton Woods em 1\% - foi expandida para 2,5\%. Assim, podemos argumentar que o Acordo Smithsoniano tentou resguardar a estabilidade monetária e financeira internacional alcançada com o Acordo de Bretton Woods.

Em julho de 1972, entretanto, o governo britânico rompeu o Acordo Smithsoniano e permitiu que a cotação da libra variasse em relação ao dólar sem limitações. Em fevereiro de 1973, face ao desrespeito europeu ao sistema de flutuação cambial controlada, o dólar já havia sofrido uma depreciação de $10 \%$ em relação à libra, ao marco alemão e ao franco francês. Esse período foi sucedido por uma corrida cambial na Europa: os governos de diversos países se livraram rapidamente de suas reservas em dólar, acentuando ainda mais a depreciação da moeda norteamericana (GUTTMANN, 1994, p.142).

Constatada a erosão do Acordo Smithsoniano, o governo norte-americano aderiu, em 1973, ao sistema de livre flutuação cambial, sem a definição de bandas de flutuação e com intervenções do Federal Reserve no mercado de câmbio. O ano de 1973 marcou a deflagração de um período de profunda instabilidade e de indefinição de regras claras para a reorganização do sistema monetário e financeiro internacional. As transformações econômicas internacionais entre 1971 e 1973 deflagraram, também, mudanças na política externa norte-americana: decisões unilaterais, comprometidas com interesses nacionais, e políticas reparatórias para lidar com as consequências dessas decisões assumiram o primeiro plano das relações entre os Estados Unidos e o resto do mundo.

A sustentação da centralidade internacional do dólar, desde a década de 1970, foi contraposta por iniciativas europeias, que sinalizavam, ainda que incipientemente, possíveis alternativas à moeda norte-americana. Desde o Acordo de Bretton Woods, cogitava-se a 
Flavio Alves Combat

possibilidade de reorganizar o sistema monetário e financeiro internacional com base numa moeda internacional - na época, o "bancor", tal como proposto por J. M. Keynes.

A acentuada desvalorização do dólar, nas décadas de 1970 e 1980, em relação ao marco alemão, ao franco francês e à libra corroborou ainda mais as propostas alternativas à centralidade internacional da moeda norte-americana. Na Europa, iniciativas a favor da reorganização do sistema monetário e financeiro internacional acentuavam a deterioração da hegemonia norteamericana. A França, por exemplo, reforçou o controle do fluxo de capitais na tentativa de reverter a instabilidade cambial. Os Estados Unidos, em contrapartida, opuseram-se à iniciativa francesa e passaram a defender a liberalização do movimento internacional de capitais (HELLEINER, 1994, p. 102-111). Naquele contexto, as discussões sobre a possibilidade de criação de uma moeda única europeia foram retomadas - proposta concretizada somente entre 1999 e 2002, com o Euro.

Ao final da década de 1970, os países da Comunidade Econômica Europeia concordaram em manter as cotações das suas moedas em relação ao dólar numa margem de flutuação de $4,5 \%$. O sistema cambial europeu inaugurado nesse período tornou-se conhecido como "serpente no túnel"vi.

O European Monetary System (EMS) foi criado, em 1979, após negociações entre os nove membros da Comunidade Econômica Europeia (CEE). O objetivo central do EMS era contribuir com a estabilização das economias europeias através da limitação coordenada da flutuação cambial. Três instituições centrais compunham o EMS: a Unidade de Conta Europeia (European Currency Unit), utilizada nas transações entre os países da CEE; o Mecanismo de Taxa de Câmbio (Exchange Rate Mechanism), através do qual os membros da CEE concordavam em manter as cotações de suas respectivas moedas numa banda de oscilação previamente acordada; e o Fundo Europeu de Cooperação Monetária (European Monetary Cooperation Fund), um fundo coletivo de reservas de divisas, que seria empregado para debelar especulações e flutuações cambiais fora das bandas consideradas adequadas. Abria-se, então, o caminho para a constituição de um sistema monetário e financeiro europeu, um subsistema regional alternativo ao sistema internacional de Bretton Woods, em franca erosão (EICHENGREEN, 2000, p. 204).

A partir de 1973, uma sucessão de regimes cambiais assinalou a dificuldade de reorganizar o sistema monetário e financeiro internacional com base em regras de conversibilidade claras e amplamente aceitas. Dentre as principais iniciativas para tentar reverter esse processo de fragilização, destacaram-se os sistemas de flutuação cambial "suja"vii e de livre flutuação cambialviii, além do Acordo do Plaza (1985) e do Acordo do Louvre (1987).

O sistema monetário e financeiro internacional, na década de 1970, foi marcado por incertezas e instabilidade. Uma tentativa do FMI, em 1972, de retomar o regime cambial de paridade fixa estabelecido em Bretton Woods falhou face às políticas cambiais adotadas na Europa. Em 1976, na Conferência da Jamaica, reconheceu-se internacionalmente o regime de flutuação cambial suja. Cada país tornou-se responsável pela definição unilateral dos limites de oscilação das taxas de câmbio de cada moeda em relação a todas as outras. O papel exercido pelo ouro nas reservas internacionais dos países foi igualmente reduzido.

A ratificação internacional do regime de flutuação cambial suja, em 1976, marcou o início do extenso período de instabilidade institucional que sucedeu o colapso do regime de Bretton Woods. Imediatamente após a Conferência da Jamaica, a maioria dos países não aderiu ao regime de flutuação cambial suja e continuou a sustentar a valorização de suas moedas em relação ao dólar. Mesmo entre os países europeus, a instabilidade das regras de conversibilidade cambial era patente. Em função da dificuldade de manter o alinhamento cambial com o dólar, a França, a Inglaterra e a Itália aderiram, por algum tempo, ao sistema de flutuação cambial mais conveniente a cada país, definindo unilateralmente a cotação entre a sua moeda e as demais. 
Flavio Alves Combat

Após 1976, os países do BENELUX (Bélgica, Holanda e Luxemburgo), além da Suécia, da Noruega e da Dinamarca, realinharam as suas moedas em relação ao marco alemão, criando uma "zona do marco" (EICHENGREEN, 2000, p. 205-207; GUTTMANN, 1994, p. 396). A referenciação das moedas europeias no marco sinalizou o fortalecimento da moeda alemã na Comunidade Econômica Europeia e a consolidação da liderança econômica exercida pela Alemanha na Europa, em clara dissonância com os interesses norte-americanos no continente. A década de 1970 foi marcada ainda pelo fortalecimento do Euromercado, cuja origem remonta à década de 1960, quando experimentou um acelerado crescimento em função dos depósitos oriundos dos países produtores de petróleo (beneficiados pela elevação do preço do petróleo em 1973 e 1979). O influxo de "petrodólares" fortaleceu o mercado financeiro europeu (com o seu centro em Londres), aumentando sensivelmente a liquidez europeia e acirrando a concorrência com o mercado financeiro nova-iorquino. Ao analisar as consequências dos choques do petróleo, na década de 1970, para o mercado financeiro internacional, Clark observou:

\begin{abstract}
O aumento do preço do petróleo inundou os membros da OPEP com dólares que excederam em muito as necessidades de investimento doméstico e, portanto, foram classificados como "petrodólares excedentes". Uma grande parte deles foi para os bancos de Londres e Nova York, onde foi iniciado o novo processo de reciclagem monetária de petrodólares. (...) A Arábia Saudita e os outros produtores da OPEP depositaram seus excedentes de dólares nos bancos dos EUA e do Reino Unido, que então pegaram esses petrodólares da OPEP e os emprestaram, como títulos ou empréstimos de "eurodólares", a governos de países em desenvolvimento que estavam desesperados por empréstimos para financiar as importações de petróleo. Embora benéfico para os centros financeiros dos EUA e do Reino Unido, o acúmulo dessas dívidas em petrodólares, no final da década de 1970, facilitou a base da crise da dívida no mundo em desenvolvimento no início da década de 1980. Centenas de bilhões de dólares foram reciclados entre a OPEP, os bancos de Londres e Nova York e de volta aos países em desenvolvimento. (CLARK, 2005, p. 21-22)
\end{abstract}

A instabilidade institucional característica do período que sucedeu o fim do padrão dólarouro tornou-se clara também em decorrência da incompatibilidade entre as políticas norteamericana e europeias de controle dos fluxos de capitais. De um lado, os Estados Unidos implementaram uma série de medidas de desregulamentação financeira: a criação do mercado futuro de câmbio na Bolsa de Chicago em 1973, a liberação do controle sobre o movimento de capitais em 1974, a desregulamentação da Bolsa de Nova York em 1975. A Europa e o Japão, por outro lado, mantiveram os mecanismos de controle sobre o fluxo de capitais. Essa dissonância entre as políticas dos Estados Unidos, da Europa e do Japão revelava a fragilidade do sistema monetário e financeiro internacional na década de 1970 (GUTTMANN, 1994, p. 148).

A hipótese de erosão do sistema monetário e financeiro internacional a partir da década de 1970 é corroborada pelas constantes intervenções dos Bancos Centrais na condução dos mercados de câmbio. De acordo com Einchengreen:

\footnotetext{
Moedas como o dólar canadense, o franco francês, o franco suíço, a lira, o iene e a libra esterlina eram administradas ativamente. Intervenções atuavam em ambos os lados do mercado: elas eram usadas para dar sustentação a moedas fracas e para limitar a valorização das moedas fortes. (EINCHENGREEN, 2000, p. 191)
}

Essas intervenções regulares transformaram, na prática, o sistema de flutuação cambial num sistema de "flutuação suja" (dirty float), o que não garantia, todavia, a reorganização do sistema monetário e financeiro internacional e o equilíbrio dos balanços de pagamentos. As intervenções dos bancos centrais eram baseadas em objetivos nacionais específicos, sobretudo no 
Flavio Alves Combat

interesse em controlar a inflação e em aumentar a competitividade internacional de cada país. Dessa forma, embora a política cambial atendesse aos objetivos imediatos de cada Estado, o resultado conjunto desse processo era a inconsistência entre as diferentes iniciativas nacionais, manifestada sob a forma de um sistema monetário e financeiro internacional em franco descompasso.

Deve-se considerar ainda que nem sempre os objetivos nacionais de cada país eram alcançados com base nessas políticas cambiais unilaterais. Na década de 1970, por exemplo, os problemas econômicos norte-americanos decorrentes da expansão dos gastos públicos e da elevação da inflação pesaram na decisão de Washington de colocar em curso uma política de desvalorização do dólar. A política de desvalorização do dólar aumentou, entretanto, as especulações contra a moeda norte-americana, gerando um efeito contrário ao pretendido.

A política de desvalorização cambial, colocada em curso pelos Estados Unidos, ameaçava os interesses da Alemanha e do Japão. As tentativas norte-americanas de harmonizar as políticas cambiais eram percebidas com desconfiança, sobretudo na Europa. Os países europeus, ao final da década de 1970, estavam mais inclinados a defender a estabilidade interna de preços, apostando no controle cambial para evitar a valorização de suas moedas, do que a proteger o dólar (EINCHENGREEN, 2000, p. 193).

A década de 1970, em que prevaleceu o sistema cambial de flutuação "suja", foi marcada, portanto, pela acentuada instabilidade e fragilização do sistema monetário e financeiro internacional, com destaque para a inexistência de regras compartilhadas de conversibilidade entre as moedas e pela erosão do Acordo de Bretton Woods.

\section{II. b) 0 sistema de livre flutuação cambial}

Na década de 1980, o desalinhamento da Europa e do Japão com as políticas norteamericanas de estabilização do dólar influenciaram a mudança de curso da política monetária e cambial dos Estados Unidos. A intensificação da tentativa norte-americana de sustentar o dólar no topo da hierarquia monetária internacional e de subordinar os outros países às necessidades econômicas dos Estados Unidos marcou um novo período do sistema monetário e financeiro internacional.

No início da década de 1980, as transformações unilaterais da política econômica norteamericana foram aprofundadas: os juros foram elevados e a base monetária foi contraída na tentativa de controlar a inflação. Os Estados Unidos aderiram ao sistema de livre flutuação cambial, expandindo, assim, o processo de desregulamentação econômica em curso desde a década anterior (EINCHENGRENN, 2000, p. 195-196).

Do lado europeu, desde final da década de 1970, já era clara a incompatibilidade entre o Sistema Monetário Europeu e as ambições norte-americanas. O Sistema Monetário Europeu, arquitetado principalmente pela Alemanha e pela França, contrapunha-se frontalmente à livre flutuação cambial e à desregulamentação econômica colocadas em curso pelos Estados Unidos. Na prática, o Sistema Monetário Europeu estabeleceu uma paridade fixa das moedas europeias em relação a uma nova unidade de conta (European Currency Unit), atrelada a uma cesta de moedas que também incluía o dólar e o ouro. Ao mesmo tempo, o SME permitia que as taxas de câmbio bilaterais oscilassem em até 2,25\%, de acordo com o previsto no Mecanismo de Taxa de Câmbio (Exchange Rate Mechanism). Esse Mecanismo previa, também, intervenções estatais caso as flutuações cambiais sinalizassem uma possível violação da margem de 2,25\%. O fundamento dessas intervenções residia no Fundo Europeu de Cooperação Monetária, um pooling de divisas utilizado para reverter oscilações cambiais bruscas (GUTTMAN, 1994, p. 399). A retomada do controle de capitais e a eventual necessidade de realinhamentos das moedas europeias eram medidas igualmente previstas. 
Flavio Alves Combat

EICHENGREEN (2000, p. 214) ressaltou as semelhanças entre o Sistema Monetário Europeu e o sistema de Bretton Woods. Num primeiro momento, as analogias são confirmadas pelo estabelecimento de normas de conversibilidade, de ajuste, de liquidez e de movimentação de capitais semelhantes aos estabelecidos em 1944. Contudo, o sistema europeu fundado na década de 1970 possuía uma diferença fundamental em relação ao sistema de Bretton Woods: uma unidade de conta supranacional que interligava os países da Europa num bloco comercial e político com significativa independência em relação aos Estados Unidos.

O Sistema Monetário Europeu assemelhava-se ao sistema monetário e financeiro internacional de Bretton Woods também no que se refere à proeminência de uma moeda no interior do sistema. O marco alemão, apesar da clara diferença em relação ao papel internacional exercido pelo dólar, tornou-se a principal moeda da Comunidade Econômica Europeia. O papel hegemônico assumido pelo marco dentro da Europa era sustentado tanto pela importância da economia alemã no continente quanto pela criação da European Currency Unit, referenciada numa cesta de moedas em que o marco alemão possuía grande peso.

As divergências entre as políticas europeias e norte-americanas foram acentuadas na primeira metade da década de 1980. A tentativa dos Estados Unidos de atrair o capital financeiro para ativos cotados em dólar aumentou a dependência externa norte-americana de capitais de curto prazo, tendência agravada pelo crescimento do déficit externo dos Estados Unidos desde a Guerra do Vietnã (HELLEINER, 1994, p. 140-145). Em 1985, a intensificação dos problemas no sistema monetário e financeiro internacional contribuiu para o abandono do sistema de livre flutuação cambial.

\section{II. c) O acordo do plaza (1985) e o acordo do louvre (1987)}

Em 22 de setembro de 1985, os países do G5 (Estados Unidos, Alemanha Ocidental, França, Japão e Grã-Bretanha) reuniram-se numa Conferência, sediada no Hotel Plaza, em Nova York, para tentar reverter a crise em curso no sistema monetário e financeiro internacional.

A política cambial norte-americana sinalizava uma possível guerra protecionista, expectativa ainda mais concreta após a acentuada desvalorização do dólar imposta por Washington a partir de fevereiro de 1985. Através do Acordo do Plaza, os países do G5 concordaram em promover uma desvalorização controlada do dólar, sobretudo em relação ao marco alemão e ao iene. Acordou-se, também, a redução dos juros nos Estados Unidos, na Alemanha e no Japão, com o propósito de colocar um ponto final na guerra pela atração de capital financeiro (EINCHENGREEN, 2000, p. 259).

O Acordo do Plaza, inicialmente, alcançou um aparente sucesso: o dólar foi desvalorizado de forma controlada, as taxas de juros foram reduzidas e as expectativas de uma guerra protecionista foram revertidas. Porém, pouco tempo depois, a política de desvalorização do dólar escapou ao controle norte-americano, sobretudo em função da indefinição de regras claras de conversibilidade cambial.

Em 1986, os Estados Unidos propuseram a reorganização do sistema monetário e financeiro internacional com base num sistema de flutuação cambial administrada, que seria pautado pelo acompanhamento de indicadores econômicos. Em caso de desajustes, os países interviriam conjuntamente. Inicialmente, a proposta foi recusada, mas face aos problemas econômicos internacionais gerados pela desvalorização descontrolada do dólar, os países do G6 (contando, então, com a participação do Canadá) reuniram-se mais uma vez, em 1987, para tentar reverter o quadro de instabilidade. 
A reunião do G6, em Paris, deu origem ao Acordo do Louvre (1987). O objetivo central do novo acordo era frear a excessiva desvalorização do dólar deflagrada no Acordo do Plaza. A estabilidade institucional era, todavia, mais uma vez aparente. EINCHENGREEN (2000, p. 200), apesar de considerar que o Acordo do Plaza marcou a criação de um "novo regime" monetário e financeiro, reconheceu que as políticas colocados em curso após 1985 em nada respeitavam as regras acordadas ${ }^{i x}$. No Acordo do Louvre, persistiu a indefinição das regras de conversibilidade e nenhum consenso sobre os limites de flutuação cambial foi alcançado.

Ainda que regras de conversibilidade e limites de flutuação cambiais tivessem sido acordados no Louvre, o resultado prático dessas medidas foi anulado pela crescente liberalização dos fluxos de capital financeiro, que abria, na prática, um vasto campo de especulação e a possibilidade de se testar os limites de flutuação cambial (GUTTMANN, 1994, p. 382).

Ao final da década de 1980, as propostas do Acordo do Plaza e do Acordo do Louvre provaram-se insustentáveis. O sistema de administração cambial administrada chegou ao fim e a desvalorização do dólar foi ainda mais acentuada. Algumas tentativas pontuais de reverter a fragilização do sistema monetário e financeiro internacional foram igualmente mal sucedidas.

\section{II. d) O sistema monetário e financeiro internacional na década de 1990}

Apesar das persistentes intervenções estatais sobre o câmbio a partir do final dos anos 1980, o início da década de 1990 sinalizava uma aparente consolidação da livre flutuação cambial . A exceção ficava por conta dos países inseridos no Sistema Monetário Europeu, que experimentaram uma relativa estabilidade numa comparação internacional. A relativa estabilidade do Sistema Monetário Europeu na segunda metade da década de 1980 e a consolidação de um mercado único europeu acentuaram a necessidade e a viabilidade de uma união monetária. A proposta de moeda única foi concretizada, em 1989, no Relatório Delors e oficializada, em 1992, no Tratado de Maastricht.

A unificação monetária europeia foi planejada em etapas e propunha a formação de uma União Monetária entre 1997 e 1999. Antes da unificação monetária, pretendia-se extinguir o controle de capitais e coordenar as políticas econômicas dos países europeus. A centralização monetária seria uma tarefa do Instituto Monetário Europeu, um predecessor do Banco Central Europeu, responsável também pela coordenação das políticas monetárias dos países da Europa.

Todavia, o processo de criação de uma moeda única europeia foi afetado pela instabilidade do sistema monetário e financeiro internacional. Apesar do esforço de coordenação europeu, a indefinição de regras internacionais de conversibilidade cambial dificultaram ainda mais as tentativas de coordenar as políticas econômicas dos países europeus. A resistência cultural à unificação monetária europeia e a queda dos regimes do Leste Europeu somaram-se às dificuldades enfrentadas pela Europa para concretizar as propostas do Tratado de Maastricht.

Em setembro de 1992, as especulações contra as moedas europeias alcançaram um pico. Em resposta, a Itália e a Grã-Bretanha abandonaram o Sistema Monetário Europeu. A Suécia e a Finlândia, que se preparavam para ingressar no sistema, retrocederam. A instabilidade cambial das moedas europeias persistiu até 1993, quando os países da Europa, liderados pela Alemanha, concordaram em afrouxar as regras de conversibilidade, aumentando as bandas de flutuação cambial para 15\% (GUTTMANN, 1994, p. 408).

A aceleração do crescimento econômico norte-americano, a partir de meados da década de 1990, agravou a instabilidade do sistema monetário e financeiro internacional. Em contraste com o relativo sucesso econômico experimentado pelos Estados Unidos, os principais países europeus, além do Japão, enfrentavam uma desaceleração econômica. A valorização excessiva do iene em relação ao dólar ameaçava, ainda, a sustentabilidade do padrão de financiamento externo da 
Flavio Alves Combat

economia norte-americana: se o governo japonês recorresse à liquidação dos títulos da dívida pública norte-americana, os Estados Unidos perderiam o apoio de seu principal financiador. Em 1995, uma nova intervenção no sistema monetário e financeiro internacional tentou reverter a valorização do iene e a desvalorização excessiva do dólar (BRENNER, 2000, p. 15).

A intervenção coordenada em 1995 foi a última iniciativa conjunta de intervenção sobre o câmbio na década de 1990. Intervenções unilaterais continuaram sendo eventualmente realizadas, muito embora, em 1997, o G7 já considerasse corrigido o desalinhamento entre o dólar e o iene.

Em 1996, a Itália e a Finlândia reingressaram no Sistema Monetário Europeu e as propostas de unificação monetária europeia foram revigoradas. O Euro tornou-se, de fato, o eixo central do novo sistema monetário e financeiro europeu e a sua consolidação marcou uma nova fase de desafios para o dólar na hierarquia monetária internacional.

\section{Conclusão}

O fim da Segunda Guerra Mundial marcou a consolidação da hegemonia dos Estados Unidos e a ascensão do dólar ao topo da hierarquia monetária internacional. O quadro dos grandes desafios confrontados por Washington logo após a Segunda Guerra Mundial foi igualmente caracterizado por um horizonte de grandes oportunidades. Empregar a superioridade econômica e política norte-americana a favor de uma configuração das relações sociais favorável aos Estados Unidos dependia claramente da capacidade norte-americana de convencer diferentes países e grupos sociais acerca da comunhão de interesses supostamente em vigor e da legitimidade social da liderança exercida pelos Estados Unidos. Naquele contexto, reorganizar o sistema monetário e financeiro internacional e contribuir com a recuperação dos principais parceiros políticos e econômicos dos Estados Unidos na Europa eram, portanto, interesses prementes da Casa Branca.

O Acordo de Bretton Woods (1944) inscreveu-se precisamente nesse contexto de desafios e oportunidades como um "centro gravitacional" da política norte-americana no período que sucedeu imediatamente a Segunda Guerra Mundial. Boa parte das estratégias traçadas por Washington para a consecução de seus objetivos e para a defesa de seus interesses girava em torno dessa iniciativa. Afinal, o papel que os Estados Unidos desejavam protagonizar na comunidade internacional dependia, claramente, das respostas norte-americanas que seriam dadas aos problemas políticos e econômicos que assolavam o mundo após 1945.

O sucesso das iniciativas políticas e econômicas norte-americanas asseguraram não apenas a consolidação da hegemonia dos Estados Unidos, mas inauguraram um período de grande prosperidade nos países do bloco capitalista que, entre 1945 e 1975, contribuiu significativamente para o amplo apoio aos interesses "universais" defendidos por Washington. Esse período se tornou conhecido como os "trinta gloriosos", a era de ouro do capitalismo.

O consenso entre capital e trabalho, característico do Estado de Bem-Estar Social dos "trinta gloriosos", e a nova arquitetura monetária e financeira internacional contribuíram com a rápida expansão do produto, da renda e da lucratividade dos Estados Unidos e de economias europeias. As principais tendências que dificultavam a reprodução ampliada do capital foram eficientemente coibidas, embora não extinguidas, elevando ainda mais a credibilidade da Casa Branca à frente da liderança hegemônica. A "great affluent society" norte-americana desfrutava, então, de uma estabilidade supostamente inabalável e repousava sobre fundamentos aparentemente sólidos.

Na década de 1960, todavia, o acirramento das tensões entre a União Soviética e os Estados Unidos pesou na decisão da maior potência mundial de intervir militarmente num país do Sudeste Asiático que pouco interessava à sociedade norte-americana. A Guerra do Vietnã (19651975) marcou uma derrota militar sem precedentes na história dos Estados Unidos e deflagrou um 
Flavio Alves Combat

processo de fragilização da hegemonia norte-americana. Face à incapacidade dos Estados Unidos sustentarem incontestavelmente a universalidade dos interesses norte-americanos e perante os incontornáveis problemas econômicos acirrados pela Guerra do Vietnã, em 1971 o padrão dólarouro foi extinto e com ele os fundamentos do sistema monetário e financeiro internacional criado, em 1944, pelo Acordo de Bretton Woods.

A crescente fragilização da hegemonia norte-americana a partir da década de 1970 caracterizada pela dificuldade norte-americana de continuar defendendo, sem grandes contestações, a validade universal dos interesses perseguidos pelos Estados Unidos - afetou sensivelmente a posição internacional do dólar. A moeda da nação hegemônica, que historicamente exerceu internacionalmente as funções de meio de pagamento e de reserva de valor, experimentou, a partir de 1971, um processo de crescente fragilização.

As contradições do dólar como moeda de referência internacional deram origem, a partir dos anos 1970, a um importante paradoxo. Como afirmar que a hegemonia dos Estados Unidos estava fragilizada desde a década de 1970 se, no mesmo período, a moeda norte-americana alcançou a mais avançada forma de moeda de crédito (sem lastro real) e, mesmo assim, mantevese no topo da hierarquia monetária internacional? Argumentei que a fragilização da hegemonia dos Estados Unidos e do dólar a partir da década de 1970 não são teses incompatíveis com a sustentação da centralidade internacional da moeda norte-americana no mesmo período.

Defendi que a manutenção da centralidade internacional do dólar, após 1971, foi assegurada, sobretudo, pela inexistência de uma nação suficientemente forte para assumir a dianteira da hegemonia mundial e depor, definitivamente, a centralidade da moeda estadunidense, bem como pelas singularidades da arquitetura mundial de poder vigente durante a Guerra Fria. No contexto das amplas rivalidades do mundo bipolar, era preferível, do ponto de vista europeu, continuar apoiando a liderança norte-americana do que apostar numa arriscada oposição ao poder dos Estados Unidos.

Sustentei, portanto, que embora, desde 1971, o sistema financeiro e monetário internacional seja fundamentado pelo padrão dólar - assentado na mais desenvolvida forma de

moeda de crédito - a capacidade dos Estados Unidos convencerem, sem grandes contestações, os outros países sobre a universalidade de seus interesses está em declínio.

Defendi, dessa forma, a ideia de que, desde o início da década de 1970, a capacidade de convencimento dos Estados Unidos (fundamento da hegemonia) enfrenta um processo de fragilização, acentuado pelas contradições do dólar no topo da hierarquia monetária internacional. Sustentei, igualmente, o peso da capacidade norte-americana em continuar centralizando a gerência do capital financeiro como uma das razões pelas quais o dólar, embora em processo de fragilização, mantém a sua centralidade na hierarquia monetária internacional.

(Recebido para publicação em agosto de 2019)

(Reapresentado em setembro de 2019)

(Aprovado para publicação em dezembro de 2019) 
Flavio Alves Combat

\section{Cite este artigo}

COMBAT, Flávio, 2019. A crise do sistema de Bretton Woods: considerações sobre o papel do dólar na hierarquia monetária internacional. Revista Estudos Políticos: a publicação semestral do Laboratório de Estudos Hum(e)anos (UFF). Rio de Janeiro, Vol.10 | N.2, pp. 245- 265, dezembro de 2019.

\section{Notas}

1. As abordagens mencionadas são extensamente analisadas por BORDO (1992, p. 10-14).

2. A esterilização monetária consiste em operações do Banco Central, com o objetivo de regular a oferta de moeda e, consequentemente, o nível de liquidez da economia, com potenciais impactos sobre a inflação.

3. Reduções acentuadas e persistentes do nível geral de preços, implicando forte desestímulo à produção doméstica.

4. Não se pretende, com esse argumento, justificar a crise do Sistema de Bretton Woods exclusivamente com base na política militar-industrial dos Estados Unidos. O objetivo é destacar a importância daquela política belicista, centrada em vultosos gastos com a máquina de guerra, para a crise de Bretton Woods, resgatando, assim, a contribuição de Mészáros ao debate.

5. O G10, em 1971, era formado por: Estados Unidos, Bélgica, Canadá, França, Itália, Japão, Holanda, Reino Unido, Alemanha e Suécia.

6. Uma alusão metafórica ao movimento de uma serpente, em referência às oscilações controladas das taxas de câmbio.

7. Sistema de taxas de câmbio sem a definição prévia de metas ou bandas de flutuação, com intervenções periódicas do Banco Central de modo a manter o câmbio no patamar considerado ideal em cada momento.

8. Sistema de taxas de câmbio teoricamente livre de intervenções da autoridade monetária, determinado exclusivamente pela demanda e a oferta de moedas. Na prática, as intervenções eram necessárias e empregadas.

9. De acordo com EINCHENGREEN (2000, p. 200, 259), as políticas cambiais europeias, norte-americana e japonesa após 1985 não foram pautadas pelo princípio da "intervenção cambial esterilizada", estabelecido no Acordo do Plaza. Portanto, as intervenções governamentais sobre o câmbio, que provocavam variações do meio circulante interno, não eram esterilizadas por operações de compra e venda de títulos no mercado doméstico, gerando assim pressões inflacionárias.

10. Em 1990, ao ser questionado sobre a política cambial norteamericana, o presidente George Bush declarou: "De vez em 
quando eu penso nisso, mas não muito" (EICHENGREEN, 2000, p. 201-202).

\section{Referências bibliográficas}

BARRETO, Álvaro Augusto de Borba. Criação de municípios no Uruguai (2009 2010): processo de inovação institucional. Revista Jus Navigandi, 2011, vol.16, n 2940, pp.1-2.

". in Enciclopédia de Guerras e Revoluções do século XX. Rio de Janeiro: Elsevier/ Campus, 2004, p.545-547.

NIPA (National Income and Product Accounts). Washington: Bureau of Economic Analysis. U.S. Department of Commerce, 1945-2006. Acesso em: 12/12/2017. Disponíveis em: http://www.bea.gov/national/index.htm

OBERDORFER, Don. The Turn: from the Cold War to a New Era. The United States and the Soviet Union, 1983-1990. Washington: Poseidon, 1991. BORDO, Michael D. The Bretton Woods International Monetary System: an Historical Overview. Massachusetts: NBER, 1992 (National Bureau of Economic Research, working paper no 4033).

BRENNER, R. The boom and the bubble. In: New Left Review, n. 6, novembro/dezembro 2000.

CLARK, William R. Petrodollar warfare. Oil, Iraq and the future of the dollar. Canada: New Society Publishers, 2005.

DUKES, Paul. The last great game: USA versus USSR. Events, conjunctures, structures. Londres: Palgrave, 1990.

EICHENGREEN, B. A Globalização do Capital. Uma história do Sistema Monetário Internacional. São Paulo: Editora 34, 2000.

FONTAINE, André. La Guerre Froide, 1917-1991. Paris: La Martinière, 2006.

GUTTMANN, Robert. How Credit-Money Shapes the Economy. The United States in a Global System. New York: M. E. Sharp, 1994.

HELLEINER, E. States and the Reemergence of Global Finance. From Bretton Woods to the 1990's. Ithaca: Cornell University Press, 1994.

HOGAN, Michael J. The Marshall Plan: America, Britain, and the reconstruction of Western Europe, 1947-1952. Cambridge: Cambridge University Press, 1987.

LUNDESTAD, Geir. Empire by invitation? The United States and Western Europe, 1945-1952. In: Journal of Peace Research, $n^{\circ}$ 23, Sept. 1986.

MÉSZÁROS, István. Produção destrutiva e Estado capitalista. São Paulo: Ensaio, 1989. 
A CRISE DO SISTEMA DE BRETTON WOODS: CONSIDERAÇÕES SOBRE O

Flavio Alves Combat

MUNHOZ, Sidnei J. Verbete "Marshall, Plano

POLLARD, Robert A. Economic security and the origins of the Cold War, 1945-1950. New York: Columbia Univ. Press, 1985.

SEYMOUR, Melman. Permanent war economy. American capitalism in decline. Nova York: Touchstone, 1974. 